\title{
A household survey of medicine storage practices in Gondar town, northwestern Ethiopia
}

\author{
Fitsum Sebsibe Teni ${ }^{1 *}$, Abdrrahman Shemsu Surur ${ }^{2}$, Assefa Belay $^{3}$, Dawit Wondimsigegn $^{4}$, \\ Dessalegn Asmelashe Gelayee ${ }^{3}$, Zewdneh Shewamene ${ }^{3}$, Befikadu Legesse ${ }^{5}$ and Eshetie Melese Birru ${ }^{3}$
}

\begin{abstract}
Background: Household surveys are crucial to get accurate information on how medicines are acquired, and used by consumers, as they provide the best evidence in the area. The objective of this study was to document household medicine storage practices in Gondar town, northwestern Ethiopia.

Methods: A cross-sectional household survey was conducted from April 5 to May 6, 2015. In the study, 809 households were surveyed from four sub-cities in the town selected through multistage sampling with 771 included in the final analysis. Data on the extent of storage, storage conditions, sources of medicines and their current status among others were collected through structured interviews and observations. The data were entered in to Epidata version 3.1, exported to and analyzed using Statistical Packages for Social Sciences (SPSS) version 21.

Results: Of the 771 households in the study, 44.2\% stored medicines. Presence of family members with chronic illness(es) and higher levels of household incomes predicted higher likelihood of medicine storage. In the households which allowed observation of stored medicines $(n=299)$, a mean of 1.85 [SD $=1.09$ ] medicines per household were found. By category, anti-infectives for systemic use (23.9\%), medicines for alimentary tract and metabolism (19.2\%) and those for cardiovascular system (17.7\%) ranked top. Among individual medicines stored, diclofenac (10.7\%), paracetamol (9.9\%) and amoxicillin (8.0\%) were on top of the list. Dispensaries (97.8\%) and physicians (83.5\%) were almost exclusive sources of medicines and advices/orders for medicines respectively. Nearly two-thirds of the medicines found were on use and a vast majority (76.5\%) were stored in chests of drawers. Proportion of expired medicines was very low (3.14\%).

Conclusions: The use of physicians' and pharmacists' advice to get medicines; use of dispensaries as principal sources, large proportion of medicines being in use and very low proportion of expiry showed good practices. However, storage places of medicines were not purpose built. Encouraging good practices through continued medicine use education and advocating appropriate medicine storage in medicine cabinets is required to improve storage conditions and consequent use of medicines.
\end{abstract}

\section{Background}

Medicines found in households are commonly sourced from health institution dispensaries through prescriptions or from pharmacies with or without prescriptions. These medicines could be in use for current illnesses or remaining from past use [1]. Expenditure on medicines takes up from nearly a third to two-fifth of health care spending in developing countries. Purchases made by

\footnotetext{
* Correspondence: fitse4@gmail.com

${ }^{1}$ Department of Pharmaceutics and Social Pharmacy, School of Pharmacy, College of Health Sciences, Addis Ababa University, Addis Ababa, Ethiopia Full list of author information is available at the end of the article
}

individual consumers constitute a major proportion of the spending, mostly for self-medication and rarely on prescriptions. Getting a good understanding of the individual consumer choices and decisions is crucial for intervention in ensuring efficient resource use. This is important as out of pocket spending by individuals is an important component of expenditures on medicine [2,3].

While indicators of access to medicines are most commonly taken from health facilities and medicine retail outlets, there is little information from consumers. Although data obtained through indicators measured at health institution levels are vital, household surveys are 
crucial to get accurate information on how medicines are acquired and used by consumers. Such studies are important as they are the best sources of evidence in the area $[1,4]$.

The extent, source and storage conditions of medicines kept at household level provide crucial information on access and medicine use. Globally studies on household use and storage of medicines have been conducted in different countries. In many of the studies significant proportions of households stored medicines in some cases with all of them keeping medicines [5-18]. In the same and other studies, considerable levels of unused and expired medicines kept at households were reported [19-25]. These medicines were stored at home reportedly due to patient deaths, recovery from disease, expiry as well as changes in medicine [26].

In Ethiopia, so far, few studies were conducted at household level to document use and storage practice of medicines. The findings showed the proportion of households which stored medicines ranged from one-fifth to more than one-half in different parts of the country [27-29]. Apart from these, medicine storage practices at household level remain unstudied. Evidence on extent and condition of storage of medicines is crucial to inform actions toward ensuring rational use. So, the objective of this study was to document household medicine storage practices among households in Gondar town in northwestern Ethiopia. It involved comprehensive assessment of the extent of storage, source, types, duration, use status as well as expiry status of the stored medicines.

\section{Methods}

\section{Study area and design}

In this study, a household survey on medicine storage practice among residents of Gondar Town in northwestern Ethiopia, was conducted. The town is located about $750 \mathrm{~km}$ away from the capital Addis Ababa, and was home to 224,000 population in 2014/15 according to Central Statistical Agency of Ethiopia (CSA) [30]. The administrative division of the town includes a total of 24 'kebeles' (the smallest administrative division), among which 12 in the urban areas are classified as sub-cities. The other 11 'kebeles' and one special 'kebele' make up the rural areas of the town. The present study was undertaken in the urban areas of the town (Gondar Town Administration. Administrative classification of kebeles in Gondar town. 2014, unpublished).

The town has various public and privately owned health institutions. The public ones include a specialized referral university hospital and a number of health centers. There are also nearly 50 clinics and one hospital in the private sector. More than 50 medicine retail outlets are also found concentrated in the urban areas of the town (Gondar Town Health Bureau. Report on the number of medicines retail outlets in Gondar town 2014, unpublished), (Amhara Regional Health Bureau. Health Management Information System (HMIS) Implementation at private facilities: advocacy 2013, unpublished).

\section{Sampling}

The number of households included in the study was determined using a single population proportion formula; assuming the proportion $(p)$ of households with at least one medicine at the time of data collection to be $50 \%$, for maximum possible sample. The margin of error ( $\delta)$ was taken to be $5 \%$ and the $z_{1-\propto}$ at $95 \%$ confidence interval (CI) was set at 1.96. Based on this the sample size was calculated using the formula: $\left[N=\frac{\left(z_{1-\alpha}\right)^{2} \times p(1-p)}{\delta^{2}}\right]$ [31]. After taking in to account a contingency of $5 \%$ and a design effect of 2 , the final sample size was calculated to be 809 households.

A multistage sampling procedure was followed in sampling the households. In the first stage four sub-cities which accounted for one-third of the sub-cities in the town were selected by simple random sampling. Then the calculated number of households was equally divided into the four kebeles. In the second stage, from the selected sub-cities households were sampled by random selection from the list of households.

\section{Data collection instrument, process and management}

An instrument composed of a structured intervieweradministered questionnaire and a structured observation checklist was used for data collection. It was developed by adapting tools used in previous studies and guidelines $[2,12]$. The adaptation involved including parts/questions of the instruments which were relevant to answer the objectives of this study. It was first prepared in English and translated in to Amharic, a language spoken in the study area, and then back translated into English to make sure it retained the intended meaning. The data collection tool is provided as a supplementary file to this manuscript [Additional file 1].

The instrument contained questions on the sociodemographic profile of the respondents and their households, the overall health situation in the household, and specifics of medicines stored. These included current use status of the medicine(s), illnesses the medicine(s) were acquired for, prescription status and source. The structured obsevation focused on the name, packaging, storage conditions and others. The instrument was pretested on 50 respondents prior to the actual data collection, which were excluded from the final analysis, and pertinent modifications were instituted based on the finding.

Data were collected from April 5 to May 6, 2015 by four data collectors, with a diploma level of qualification in pharmacy, after a thorough one day training. The 
training focused on the data collection instruments and the appropriate approaches required in interacting with and securing consent of respondents.

Respondents approached in the study were adults available in the selected households during data collection. Whenever more than one willing adults were found, priority was given to the one deemed more informed on the health related issues of the household. In case of unavailability of eligible respondents a second visit was made. If this failed, the household next to it was included in the survey instead.

\section{Data entry, analysis and interpretation}

The collected data was coded and entered using Epidata version 3.1 (Epidata Association, Odense, Denmark). It was then exported to and analyzed by using Statistical Packages for Social Sciences (SPSS) version 21 (IBM Corp. IBM SPSS Statistics for Windows, Armonk, NY: IBM Corp. Released 2012). Data on medicines recorded from the observation in the households were categorized using the World Health Organization (WHO) Anatomical Therapeutic Chemical (ATC) classification system level one [32]. Descriptive analyses were performed by frequency and mean, with results presented in tables and bar charts. In the analysis of the association between socio-demographic as well as other related variables and medication storage practices, independent samples $\mathrm{T}$ tests, one way analysis of variance (one way ANOVA) and binary logistic regression tests were undertaken. A $p$-value cut off point of 0.05 at $95 \%$ CI was used to determine statistical significance of association.

\section{Results}

\section{Socio-demographic profile of respondents and their households}

From the 809 households in the study, surveys of the 771 were deemed complete and included in the final analysis making the response rate $95.3 \%$. Of the participants of the study who represented their respective households, upwards of three quarters (76.3\%) and two-fifths (40.9\%) were female and those in the age group of 18 to 29 years, respectively. Nearly three-fourths (73.3\%) followed Orthodox Christianity and almost all (90.3) were Amhara in their ethnic identity (Table 1).

Nearly a third (32.3\%) and more than a fifth $(22.7 \%)$ of the respondents were at secondary and college/university education level, respectively. In the overwhelming majority (84.5\%) of the households, the highest level of education reported was secondary or higher education level. Housewives accounted for the largest proportion (40.3\%) of respondents as to occupational status. In terms of income, more than one-fifth $(21.3 \%)$ of the households reported monthly earnings of 50 United States Dollars (USD) followed by those earning 51 to
Table 1 Socio-demographic characteristics of respondents and their households, Gondar Town, 2015

\begin{tabular}{|c|c|c|}
\hline Variable & & Frequency (\%) \\
\hline \multirow[t]{2}{*}{ Sex } & Male & $183(23.7)$ \\
\hline & Female & $588(76.3)$ \\
\hline \multirow[t]{5}{*}{ Age (years) } & $18-29$ & $315(40.9)$ \\
\hline & $30-39$ & $177(23.0)$ \\
\hline & $40-49$ & $127(16.5)$ \\
\hline & $50-59$ & $68(8.8)$ \\
\hline & $60+$ & $84(10.9)$ \\
\hline \multirow[t]{4}{*}{ Religion } & Orthodox Christianity & $565(73.3)$ \\
\hline & Islam & 159 (20.6) \\
\hline & Protestantism & $31(4.0)$ \\
\hline & Others $^{a}$ & $16(2.1)$ \\
\hline \multirow[t]{3}{*}{ Ethnicity } & Amhara & $696(90.3)$ \\
\hline & Tigre & $47(6.1)$ \\
\hline & Others $^{b}$ & $28(3.6)$ \\
\hline \multirow[t]{5}{*}{ Educational status } & Can't read or write & $162(21.0)$ \\
\hline & Can read and write & $87(11.3)$ \\
\hline & Primary education & $98(12.7)$ \\
\hline & Secondary education & $249(32.3)$ \\
\hline & College/university education & $175(22.7)$ \\
\hline \multirow{4}{*}{$\begin{array}{l}\text { Highest education level } \\
\text { in family }\end{array}$} & Reading and writing & $26(3.4)$ \\
\hline & Primary education & $94(12.2)$ \\
\hline & Secondary education & $234(30.4)$ \\
\hline & College/university education & $417(54.1)$ \\
\hline \multirow[t]{8}{*}{ Occupation } & Not working/unemployed & $36(4.7)$ \\
\hline & Housewife & $311(40.3)$ \\
\hline & Student & $49(6.4)$ \\
\hline & Retiree & $30(3.9)$ \\
\hline & Government employee & $106(13.7)$ \\
\hline & Private company employee & $95(12.3)$ \\
\hline & Merchant & $141(18.3)$ \\
\hline & Farmer & $3(0.4)$ \\
\hline \multirow{7}{*}{$\begin{array}{l}\text { Family's monthly income } \\
\text { (USD) }\end{array}$} & Up to 50 & $164(21.3)$ \\
\hline & 51 to 100 & $137(17.8)$ \\
\hline & 101 to 150 & 110 (14.3) \\
\hline & 151 to 200 & $76(9.9)$ \\
\hline & 200 to 250 & $80(10.4)$ \\
\hline & $>250$ & $56(7.3)$ \\
\hline & Not disclosed & $148(19.2)$ \\
\hline
\end{tabular}

a Judaism, Catholicism

b Qimant, Oromo

100 USD (17.8\%). Nearly a fifth of the households (19.2\%) did not disclose their monthly earnings (Table 1). 
Number of medicines stored in the households

Of the total 771 households included in the analysis, 341 (44.2\%) had kept medicines at home during data collection. However, 42 (12.3\%) of these households were unable or unwilling to show the medicines. In the 299 households where it was possible to observe medicines stored, an average of 1.85 [SD $=1.09$ ] medicines per household were found. These were constituted by 93 different medicines. Looking at the number of medicines stored, about half (46.5\%) of the households stored one medicine (Fig. 1).

Based on independent samples $T$ test, a statistically significant higher mean number of medicines were stored in households where family members with chronic illnesses $(p$-value $<0.01)$ lived. However, presence of a health professional in the household, did not show such a difference (Table 2).

Monthly income of a family and highest education levels attained in households did not show a statistically significant difference in the number of medicines kept at home (Table 3).

\section{Types and purposes of medicines stored}

On the basis of ATC classification, anti infectives for systemic use ranked first accounting for nearly a quarter (23.9\%) of the medicines kept at home. These were followed by medicines for alimentary tract and metabolism (19.2\%) and those for cardiovascular system (17.7\%) (Fig. 2).

Diclofenac, paracetamol and amoxicillin accounted for the most frequently stored individual medicines with proportions of $10.7 \%, 9.9 \%$ and $8.0 \%$ in that order. Only eight among the 93 different medicines kept in the households made up half $(50.5 \%)$ of the total 553 medicines found (Table 4).
Table 2 Statistical (independent T) tests assessing difference in the mean number of medicines stored by household situations, Gondar town, $2015(n=299)$

\begin{tabular}{|c|c|c|}
\hline \multirow[t]{2}{*}{ Variable } & \multicolumn{2}{|c|}{ Number of medicines stored } \\
\hline & Mean (SD) & $p$-value \\
\hline \multicolumn{3}{|c|}{$\begin{array}{l}\text { Member with chronic } \\
\text { illness }\end{array}$} \\
\hline Yes & $2.15(1.294)$ & $<.001^{*}$ \\
\hline No & $1.62(0.842)$ & \\
\hline \multicolumn{3}{|c|}{$\begin{array}{l}\text { Presence of a health } \\
\text { professional in the } \\
\text { household }\end{array}$} \\
\hline Yes & $1.84(0.943)$ & 0.929 \\
\hline No & 1.85 (1.119) & \\
\hline
\end{tabular}

The medicines observed in the households were reportedly acquired for managing different health problems/illnesses. These included 39 different illnesses/conditions reported by the households with a total frequency of 452 . Of the ten most frequently reported illnesses or conditions for which medicines were taken and kept in the households, headache (16.4\%), hypertension (13.9\%) and diabetes mellitus $(10.8 \%)$ ranked in the first three (Table 5).

\section{Storage place, current status and sources of medicines}

Of the total 553 medicines stored, more than three quarters $(80.8 \%)$ were of solid dosage forms. More than half (53.3\%) of the medicines were on use by the persons for which they were originally acquired; while about a sixth (16.1\%) of them were kept with no purpose in the households (Table 6).

The vast majority $(83.5 \%)$ of the medicines observed were reported to be acquired through physician prescriptions; while nearly a tenth $(9.2 \%)$ were gained through

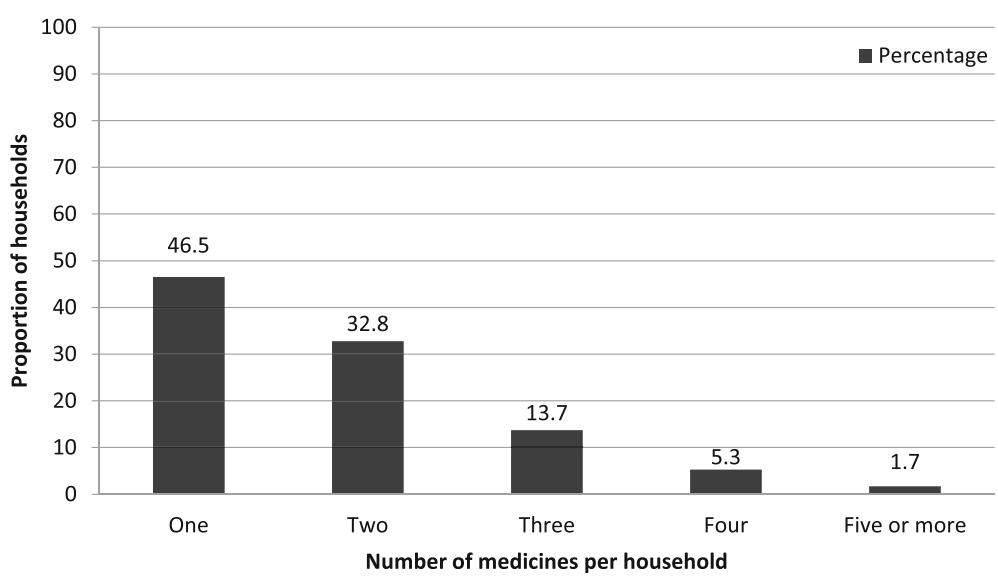

Fig. 1 Percentage distribution of households by number of medicines stored ( $n=299$ households) 
Table 3 Statistical (One-way ANOVA) tests assessing difference in the mean number of medicines stored by household situations, Gondar town, $2015(n=299)$

\begin{tabular}{llc}
\hline Variable & \multicolumn{2}{c}{ Number of medicines stored } \\
\cline { 2 - 3 } & Mean (SD) & p-value \\
\hline Family's monthly income (USD) & & \\
Up to 50 & $1.74(0.953)$ & 0.785 \\
51 to 100 & $1.88(1.036)$ & \\
101 to 150 & $1.80(0.808)$ & \\
151 to 200 & $1.92(1.025)$ & \\
200 to 250 & $1.76(0.932)$ & 0.952 \\
$>250$ & $1.78(0.751)$ \\
Not disclosed & $2.11(1.909)$ & \\
Highest education level in the family & \\
Reading and writing & $1.60(1.342)$ \\
Primary education & $1.79(0.918)$ \\
Secondary education & $1.85(0.969)$ \\
College/university education & $1.86(1.152)$ & \\
\hline
\end{tabular}

request by individuals taking the medicines or by family members. As to sources of medicines, government run health institution dispensaries (health centers and the hospital) (45.4\%) and private medicine retail outlets (pharmacies and drug stores) (41.2\%) were reported to be principal sources. The most commonly cited reasons for acquiring medicines from the preferred sources included distance from the source, mentioned by nearly half of the respondents (43.4\%). Chest of drawers in living rooms and bed rooms were spots of storage of medicines in more than three quarters $(76.5 \%)$ of the households (Table 6).

The medicines found were kept from one to as long as 730 days with a median of 15 days (Inter-quartile range
Table 4 The most frequently stored medicines in households, Gondar town, 2015 ( $n=553$ medicines)

\begin{tabular}{ll}
\hline Medicine name & Frequency (\%) \\
\hline Diclofenac & $59(10.7)$ \\
Paracetamol & $55(9.9)$ \\
Amoxicillin & $44(8.0)$ \\
Hydrochlorothiazide & $36(6.5)$ \\
Enalapril & $25(4.5)$ \\
Metformin & $23(4.2)$ \\
Glibenclamide & $22(4.0)$ \\
Omeprazole & $15(2.7)$ \\
Insulin & $13(2.4)$ \\
Metronidazole & $13(2.4)$ \\
Nifedipine & $13(2.4)$ \\
Cotrimoxazole & $12(2.2)$ \\
Ciprofloxacin & $10(1.8)$ \\
Doxycycline & $8(1.4)$ \\
Tetracycline & $8(1.4)$
\end{tabular}

$=23$ days). Among the total number of medicines, 541 had their expiry dates recorded on their packaging. Of these, 17 (3.14\%) were expired.

\section{Predictors of medicine storage in the households}

Binary logistic regression tests showed that households with a family member having chronic illness were nearly 15 times (Adjusted OR $(\mathrm{AOR})=14.824,95 \% \mathrm{CI}=9.072$ 24.222) more likely to keep medicines in their households compared to those with no such members after controlling for other variables. Higher income levels were also associated with increased likelihood of keeping medicines in the households with statistical significance

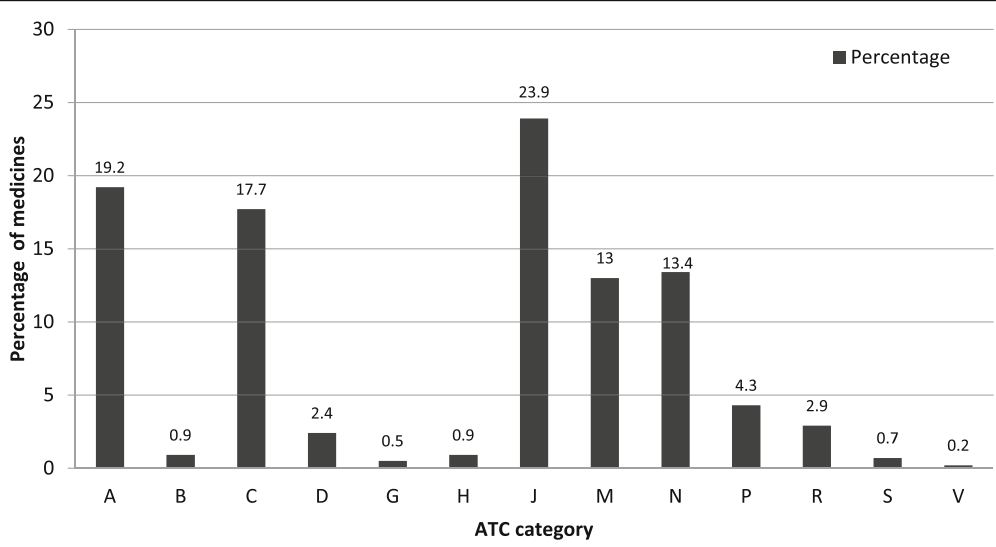

Fig. 2 Percentage distribution of medicines at level one ATC classes stored in households, Gondar town, 2015 ( $n=553$ medicines); Legend: A = Alimentary tract and metabolism, B = Blood and blood forming organs, $C=$ Cardiovascular system, $\mathrm{D}=$ Dermatologicals, $\mathrm{G}=$ Genitourinary system and sex hormones, $H=$ Systemic hormonal preparations excluding sex hormones and insulins, $\mathrm{J}=$ = Antiinfectives for systemic use, $\mathrm{M}=$ Musculo-skeletal system, $\mathrm{N}=$ Nervous system, $P=$ Antiparasitic products, insecticides and repellents $R=$ Respiratory system $S=$ Sensory organs $V=$ Various 
Table 5 The ten most frequently reported illnesses/conditions for which medicines were kept in the households, Gondar Town, 2015 ( $n=452$ illnesses/conditions)

\begin{tabular}{ll}
\hline Reported illness/condition & Frequency (\%) \\
\hline Headache & $74(16.4)$ \\
Hypertension & $63(13.9)$ \\
Diabetes mellitus & $49(10.8)$ \\
Unspecified & $29(6.4)$ \\
Fever & $26(5.8)$ \\
Eye problem & $18(4.0)$ \\
Tonsilitis & $16(3.5)$ \\
Peptic ulcer disease & $15(3.3)$ \\
Asthma & $13(2.9)$ \\
Pain & $13(2.9)$ \\
\hline
\end{tabular}

in specific income categories compared to households earning up to 50 USD per month (Table 7).

\section{Discussion}

Nearly half of the total households in this study stored medicines which was much lower compared to studies in countries like Indonesia, Iran, Iraq, Oman, Greece and USA where 82 to $100 \%$ of households did so [9-12, 18, 33]. This could be attributed to the difference in the economic development level between Ethiopia and the compared countries. This in turn could be translated in to difference in access to medicines, health insurance schemes as well as difference in the trend of self medication practice. However, the finding from the current study was higher compared to studies from northern Uganda as well as Addis Ababa and Tigray in Ethiopia; and was comparable to another study in southwestern Ethiopia [8, 27-29].

In terms of likelihood of storing medicines, households with members having chronic illnesses(es) were more likely to keep medicines compared to those without such individuals. Higher monthly income was also associated to higher likelihood of medicine storage. Similar findings have been reported by other studies also $[8,25]$.

The mean number of medicines found per household, in the current survey, was much lower compared to findings from Asia and Europe, where medicines ranging from five to 31 were found stored at home $[9,11,12,17$, 33]. The difference here could similarly be explained by the above mentioned differences between Ethiopia and the compared countries. Studies from two towns in Ethiopia, however, reported similar number of medicines per household to the present finding $[28,29]$.

Households where member with chronic illness(s) lived had higher mean number of medicines compared to those with no members with such conditions, in a statistically significant manner. The nature of the diseases which require a number of medicines over an extended period of
Table 6 Features of medicines stored in households, Gondar town, $2015(n=553)$

\begin{tabular}{|c|c|c|}
\hline \multicolumn{2}{|l|}{ Variable } & \multirow{2}{*}{$\frac{\text { Frequency (\%) }}{447(80.8)}$} \\
\hline Dosage forms & Solid & \\
\hline & Semisolid & $14(2.5)$ \\
\hline & Liquid & $92(16.6)$ \\
\hline \multirow[t]{4}{*}{$\begin{array}{l}\text { Current status } \\
\text { of medicine }\end{array}$} & $\begin{array}{l}\text { On use by the person originally } \\
\text { intended for }\end{array}$ & $295(53.3)$ \\
\hline & On use by another person & $30(5.4)$ \\
\hline & Kept for future use & $139(25.1)$ \\
\hline & Kept with no purpose & $89(16.1)$ \\
\hline \multirow[t]{6}{*}{ Storage place } & Drawer & $423(76.5)$ \\
\hline & Refrigerator & $29(5.2)$ \\
\hline & Table & $30(5.4)$ \\
\hline & Bag/purse & $22(4.0)$ \\
\hline & Pockets on cloth & $11(2.0)$ \\
\hline & Others $^{a}$ & $38(6.9)$ \\
\hline \multirow{3}{*}{$\begin{array}{l}\text { Source of advice } \\
\text { for medicine }\end{array}$} & Self-initiated & $51(9.2)$ \\
\hline & Pharmacist & $40(7.2)$ \\
\hline & Physician & $462(83.5)$ \\
\hline \multirow[t]{4}{*}{ Source of medicines } & $\begin{array}{l}\text { Government health institution } \\
\text { dispensary }\end{array}$ & $251(45.4)$ \\
\hline & Private medicine retail outlets & $228(41.2)$ \\
\hline & Aid organization pharmacy & $62(11.2)$ \\
\hline & Others $^{b}$ & $12(2.2)$ \\
\hline \multirow{7}{*}{$\begin{array}{l}\text { Reason for choosing } \\
\text { source }\end{array}$} & Short distance/proximity & $240(43.4)$ \\
\hline & Quality of services & $35(6.3)$ \\
\hline & Urgency to medicines & $45(8.1)$ \\
\hline & Had follow up at source & $82(14.8)$ \\
\hline & Availability of medicines & $15(2.7)$ \\
\hline & Fairness of price & $76(13.7)$ \\
\hline & Others $^{c}$ & $59(10.7)$ \\
\hline
\end{tabular}

a by window, under mattress, hung in plastic bags

${ }^{b}$ private clinic, sent from abroad

c free of fee services, relationships, agreement with employers

time could be a reason for this. Other variables like, presence of health professionals, highest education level in the household, monthly income of the households did not differ in a statistically significant manner with the mean number of medicines stored.

The ATC Level One categories of medicines were constituted by anti-infectives for systemic use, medicines used for the alimentary tract and metabolism as well as those used for the cardiovascular system as the top three. Studies in Uganda, Iraq, Oman and Greece reported similar findings $[8,11,12,33]$. Findings consistent with the present study were also found by other studies in Ethiopia [27-29]. Diclofenac, paracetamol and amoxicillin ranked top among medicines found, with similar findings reported in other studies [8, 10, 28]. 
Table 7 Binary logistic regression test for predictors of presence of medicines in households, Gondar town, $2015(n=771)$

\begin{tabular}{|c|c|c|c|c|}
\hline \multirow[t]{2}{*}{ Variable } & \multicolumn{2}{|c|}{ Medicines in household } & \multirow[t]{2}{*}{ OR $(95 \% \mathrm{Cl})$} & \multirow[t]{2}{*}{ AOR (95\% Cl) } \\
\hline & Yes (\%) & No (\%) & & \\
\hline \multicolumn{5}{|l|}{$\begin{array}{l}\text { Highest level of education in } \\
\text { the family }\end{array}$} \\
\hline Reading and writing & $6(23.1)$ & $20(76.9)$ & 1 & 1 \\
\hline Primary education & $22(23.4)$ & $72(76.6)$ & $1.019[0.364-2.852]$ & $1.120[0.343-3.662]$ \\
\hline Secondary education & $98(41.9)$ & $136(58.1)$ & $2.402[0.930-6.202]$ & $2.582[0.858-7.771]$ \\
\hline College/university education & $215(51.6)$ & $202(48.4)$ & $3.548[1.397-9.013]^{*}$ & $2.542[0.833-7.756]$ \\
\hline \multicolumn{5}{|l|}{$\begin{array}{l}\text { Presence of a health professional } \\
\text { in household }\end{array}$} \\
\hline Yes & $57(52.8)$ & $51(47.2)$ & $1.492[0.992-2.243]$ & $0.853[0.513-1.418]$ \\
\hline No & $284(42.8)$ & $379(57.2)$ & 1 & 1 \\
\hline \multicolumn{5}{|l|}{$\begin{array}{l}\text { Persons with chronic illness } \\
\text { in household }\end{array}$} \\
\hline Yes & $150(86.7)$ & $23(13.3)$ & $13.897[8.674-22.266]^{*}$ & $14.824[9.072-24.222]^{*}$ \\
\hline No & $191(31.9)$ & $407(68.1)$ & 1 & 1 \\
\hline \multicolumn{5}{|l|}{ Household monthly income (USD) } \\
\hline Up to 50 & $54(32.9)$ & $110(67.1)$ & 1 & 1 \\
\hline $51-100$ & $63(46.0)$ & $74(54.0)$ & $1.734[1.086-2.769]^{*}$ & $1.402[0.814-2.414]$ \\
\hline $101-150$ & $59(53.6)$ & $51(46.4)$ & $2.357[1.434-3.872]^{*}$ & $1.813[1.002-3.278]^{*}$ \\
\hline $151-200$ & $43(56.6)$ & $33(43.4)$ & $2.654[1.519-4.639]^{*}$ & $2.203[1.130-4.296]^{*}$ \\
\hline $201-250$ & $45(56.3)$ & $35(43.8)$ & $2.619[1.513-4.534]^{*}$ & $1.933[0.971-3.848]$ \\
\hline$>250$ & $32(57.1)$ & $24(42.9)$ & $2.716[1.459-5.056]^{*}$ & $2.518[1.215-5.221]^{*}$ \\
\hline Not disclosed & $45(30.4)$ & $103(69.6)$ & 0.890 [0.552-1.436] & 0.748 [0.431-1.299] \\
\hline
\end{tabular}

${ }^{*} p$ value $<0.05$

Most of the medicines were of solid dosage forms (80\%) as also reported in other studies $[8,29]$.

Nearly two-thirds of the medicines kept at home were being used/taken. This was higher compared to findings in Uganda (48\%), Indonesia and Iraq (31\% each), [8, 9, 11]. This showed a good practice in relation to household medicines use in the town as it helps reduce wastage of useful medicines and risks from unused medicines.

Chest of drawers found in living rooms as well as bedrooms were reported as principal storages in three-quarters of the households. However, medicine cabinets dedicated for medicine storage were not found. Similarly drawers were the major storage spots as reported by another study in Ethiopia [21]. However in Iran and Oman refrigerators were reported as major storage places while a study in New Zealand reported kitchens as major storage rooms $[10,12,16]$.

Almost all of the medicines assessed were advised to be acquired by physicians (83.5\%) through prescriptions which was similar to a finding in Oman [12]. This could indicate a lower level of self-medication practice among the households. The finding was very much higher compared to a study in Iraq which reported only about a third of the medicines were prescribed by physicians [11].
Virtually all of the medicines found stored in the surveyed households were acquired from pharmacies be they of public, private or aid organizations ownership. This is an encouraging practice which can help minimize the risk to patients due to buying medicines of questionable quality from informal/illegal sources. Similar practices were reported by other studies $[8,9,12]$.

Of medicines with recorded expiry date, 3.14\% were found to be expired which was comparable to a finding by another study in Tigray region of Ethiopia [29]. However, much higher proportions of expired medicines were recorded by studies in different countries in the Middle East [11, 12, 24, 25]. The very low proportion of expired medicines could be associated to the fact that the median duration of storage of medicines was only 15 days which shows medicines were not kept for very long time in most of the households.

\section{Limitations}

The present study did not include the rural parts of Gondar Town. The findings are not representative of the pattern of household medicine storage practice in those areas. 


\section{Conclusions}

Nearly half of the households stored medicines mostly acquired through physician advise almost entirely from dispensaries. Most of medicines kept at home were on use and were kept mostly in chests of drawers with no medicine cabinets in use. A very low proportion of the medicines were found to be expired.

The good practices should be encouraged through continued health education at health institutions and medicine retail outlets. Installing cabinets dedicated for medicine storage at households should be advocated by the town's health bureau to improve storage conditions of medicines.

\section{Additional file}

Additional file 1: Data collection instrument used in the data collection. (PDF $67 \mathrm{~kb}$ )

\section{Abbreviations}

ANOVA: Analysis of variance; AOR: Adjusted odds ratio; ATC: Anatomica Therapeutic Chemical; CSA: Central Statistical Agency; OR: Odds ratio; SD: Standard deviation; SPSS: Statistical Packages for Social Sciences; USD: United States Dollar; WHO: World Health Organization

\section{Acknowledgements}

The authors would like to extend their acknowledgement to the participants of the study for their willingness and time. The authors also appreciate the efforts of Adugna Sitotie, Asemachew Lakie, Eyob Mengesha and Zemene Demelash during the data collection.

\section{Funding}

The study was funded by the College of Medicine and Health Sciences, University of Gondar. The funding institution had no role in the design of the study; collection, analysis and interpretation of data and in writing the manuscript.

\section{Availability of data and materials}

The datasets generated and/or analyzed during the current study are not publicly available due requirement of confidentiality up on which the study was approved by the ethical review committee and consent was secured from participants. However, they are available from the corresponding author on reasonable request.

\section{Authors' contributions}

FST: conceived the study, FST, ASS, AB, DW, DAG, ZS, BL and EMB: were involved in the development of the proposal, prepared data collection instrument, supervised data collection, FST: performed analysis and interpretation of the data, drafted the manuscript, FST, ASS, AB, DW, DAG, ZS $B L$ and EMB: revised and approved the submission of the manuscript.

\section{Competing interests}

The authors declare that they have no competing interests.

\section{Consent for publication}

Not applicable

\section{Ethics approval and consent to participate}

The proposal for this study was submitted for review by the Ethical Review Committee of the College of Medicine and Health Sciences at University of Gondar; and it was provided with an ethical approval by the same. In addition, during the data collection at individual households, respondents were asked for their verbal consent to participate in the survey; and to show the medicines kept in their households after explanation of the purpose of the study. Verbal consent was asked because the study did not pose any risk to participants; and different levels of education/literacy among participants was expected. This was approved by the Ethical Review Committee. In the study, the decisions of respondents on participation and showing data collectors the medicines kept in their households was respected.

Furthermore, the data collection instruments did not have any personal identifiers, instead codes were employed. The data collected in such a manner were kept strictly confidential and used only for the purpose of the study. The analysis of the findings from the survey was conducted in aggregate.

\section{Publisher's Note}

Springer Nature remains neutral with regard to jurisdictional claims in published maps and institutional affiliations.

\section{Author details}

${ }^{1}$ Department of Pharmaceutics and Social Pharmacy, School of Pharmacy, College of Health Sciences, Addis Ababa University, Addis Ababa, Ethiopia. ${ }^{2}$ Department of Pharmaceutical Chemistry, School of Pharmacy, College of Medicine and Health Sciences, University of Gondar, Gondar, Ethiopia.

${ }^{3}$ Department of Pharmacology, School of Pharmacy, College of Medicine and Health Sciences, University of Gondar, Gondar, Ethiopia. ${ }^{4}$ Department of Pharmaceutics and Social Pharmacy, School of Pharmacy, College of Medicine and Health Sciences, University of Gondar, Gondar, Ethiopia. ${ }^{5}$ Department of Public Health Sciences, Karolinska Institute, Stockholm, Sweden.

Received: 26 March 2016 Accepted: 1 March 2017

Published online: 09 March 2017

\section{References}

1. World Health Organization (WHO) International Working Group for Drug Statistics Methodology, WHO Collaborating Centre for Drug Statistics Methodology, WHO Collaborating Centre for Drug Utilization Research and Clinical Pharmacological Services. Introduction to drug utilization research. World Health Organization 2003.

2. Hardon A, Hodgkin C, Fresle D. How to investigate the use of medicines by consumers. World Health Organization/University of Amsterdam/Royal Topical Institute. Geneva: World Health Organization; 2004.

3. de Joncheere $\mathrm{K}$, Rietveld AH, Huttin C. Experiences with generics. International Journal of Risk \& Safety in Medicine Prices, affordability and cost containment. In: Dukes MNG, Haaijer-Ruskamp FM, de Joncheere CP, Rietveld AH, editors. Drugs and money. 2nd ed. Amsterdam: Ios Press; 2003.

4. World Health Organization. Manual for the Household Survey to Measure Access and Use of Medicines. World Health Organization 2008. Geneva. Available: http://www.who.int/medicines/areas/coordination/household_ manual_february_2008.pdf. Accessed 23 Dec 2014

5. Arhinful DK. WHO level II household survey to measure access to and use of medicines in Ghana. WHO medicines survey conducted in Ghana in May/June 2008. Ministry of Health, Ghana. 2011. Available: http://apps.who.int/ medicinedocs/documents/s17742en/s17742en.pdf. Accessed 04 March 2017.

6. Kalyango JN, Hall M, Karamagi C. Home medication management practices and associated factors among patients with selected chronic diseases in a community pharmacy in Uganda. BMC Health Serv Res. 2012;12:323.

7. Tourinho FSV, Bucaretchi F, Stephan C, Cordeiro R. Home medicine chests and their relationship with self-medication in children and adolescents. J Pediatr (Rio J). 2008:84(5):416-22.

8. Ocan M, Bbosa GS, Waako P, Ogwal-Okeng J, Obua C. Factors predicting home storage of medicines in Northern Uganda. BMC Public Health. 2014;14:650.

9. Gitawati R. Pattern of household drug storage. Jurnal Kesehatan Masyarakat Nasional. 2014;9(1):27-31

10. Foroutan B, Foroutan R. Household storage of medicines and selfmedication practices in south-east Islamic Republic of Iran. East Mediterr Health J. 2014;20(9):548-53.

11. Jassim AM. In-home drug storage and self-medication with antimicrobial drugs in Basrah, Iraq. OMJ. 2010;25:79-87.

12. Sultanate of Oman Ministry of Health. Household survey on medicine use in Oman. Directorate of Rational Use of Medicines Ministry of Health Muscat, Sultanate of Oman 2009. Available: http://apps.who.int/medicinedocs/ documents/s17055e/s17055e.pdf. Accessed 12 Mar 2014.

13. Enato EFO, Sounyo AA, Einarson TR. Drug storage practices in the developing world: a survey of Nigerian households. J Pharm Allied Sci. 2011;8(1):1228-34. 
14. Sharif SI, Abduelkarem AR, Bustami HA, Haddad LI, Khalil DS. Trends of home drug storage and use in different regions across the northern United Arab Emirates. Med Princ Pract. 2010;19:355-8. doi:10.1159/000316372.

15. Paniz VMV, Fassa AG, Maia MFS, Domingues MR, Bertoldi AD. Measuring access to medicines: a review of quantitative methods used in household surveys. BMC Health Serv Res. 2010;10:146.

16. Hewson C, Shen CC, Strachan C, Norris P. Personal medicines storage in New Zealand. J Prim Health Care. 2013;5(2):146-50.

17. De Bolle L, Mehuys E, Adriaens E, Remon J, Van Bortel L, Christiaens T. Home medication cabinets and self-medication: a source of potential health threats? Ann Pharmacother. 2008:42:572-9.

18. Wieczorkiewicz SM, Kassamali Z, Danziger LH. Behind closed doors: medication storage and disposal in the home. Ann Pharmacother. 2013;47:482-9.

19. Al-Azzam S, Khader Y, Rawashdeh S, Hijazi S. An assessment of the Extent of Medication Wastage among Families in Jordan. Jordan J Pharm Sci. 2012:5(1):65-73.

20. Sooksriwong C, Jarupas C, Chinawong D, Supakul S, Ploylermsang C, Sornlumlertwanich $\mathrm{K}$, et al. Values of leftover drugs in households: preliminary study in 5 major Thai cities. JAASP. 2013;2:235-42.

21. Law AV, Sakharkar P, Zargarzadeh A, Bilvick BW, Hess K, Hata M, et al. Taking stock of medication wastage: Unused medications in US households. Res Soc Adm Pharm. 2015;11:571-8.

22. West LM. Medication wastage: the current situation. J Malta College of Pharmacy Practice. 2015;21:25-8.

23. Vogler S, Leopold C, Zuidberg C, Habl C. Medicines discarded in household garbage: analysis of a pharmaceutical waste sample in Vienna. J Pharm Policy and Pract. 2014;7:6.

24. Abou-Auda HS. An economic assessment of the extent of medication use and wastage among families in Saudi Arabia and Arabian Gulf countries. Clin Ther. 2003;25(4):1276-92.

25. Zargarzadeh AH, Tavakoli N, Hassanzadeh A. A survey on the extent of medication storage and wastage in urban Iranian households. Clin Ther. 2005;27(6):970-8.

26. West $L M$, Diack L, Cordina M, Stewart D. A systematic review of the literature on 'medication wastage': an exploration of causative factors and effect of interventions. Int J Clin Pharm. 2014;36:873-81.

27. Amare G, Gedif T, Alemayehu T, Tesfahun B. Pattern of drug use in Addis Ababa community. East Afr Med J. 1997:74(6):362-7.

28. Sado E, Gedif T. Drug utilization at household level in Nekemte Town and surrounding rural areas, western Ethiopia: a cross-sectional study. Open Access Library Journal. 2014;1:1-9. doi:10.4236/oalib.1100651.

29. Wondimu A, Molla F, Demeke B, Eticha T, Assen A, Abrha S, et al. Household storage of medicines and associated factors in tigray region, northern Ethiopia. PLoS One. 2015;10(8):e0135650. doi:10.1371/journal.pone.013565.

30. Federal Democratic Republic of Ethiopia Central Statistical Agency. Population projection of Ethiopia for all regions at Wereda level from 2014-2017. Addis Ababa. 2013. Available: http://www.csa.gov.et/index.php/ehioinfointernal?download=724:population-projection-of-ethiopia-for-all-regionsatwereda-level-from-2014-2017\&start=5. Accessed 04 March 2017.

31. Lwanga SK, Lemeshow S. Sample Size Determination for Health Studies: A Practical Manual. Geneva: World Health Organization; 1991. p. 1-5.

32. WHO Collaborating Centre for Drug Statistics Methodology. Guidelines for ATC classification and DDD assignment2015.WHO Collaborating Centre for Drug Statistics Methodology, Oslo, 2014

33. Tsiligianni IG, Delgatty C, Alegakis A, Lionis C. A household survey on the extent of home medication storage: a cross-sectional study from rural Crete, Greece. Eur J Gen Pract. 2012;18:3-8.

\section{Submit your next manuscript to BioMed Central and we will help you at every step:}

- We accept pre-submission inquiries

- Our selector tool helps you to find the most relevant journal

- We provide round the clock customer support

- Convenient online submission

- Thorough peer review

- Inclusion in PubMed and all major indexing services

- Maximum visibility for your research

Submit your manuscript at www.biomedcentral.com/submit
Biomed Central 